\title{
A revision of the ant genus Probolomyrmex (Hymenoptera: Formicidae: Proceratiinae) in Australia and Melanesia
}

\author{
S.O. SHATTUCK ${ }^{1}$, N.R. GUNAWARDENE ${ }^{2} \&$ B. HETERICK ${ }^{2}$ \\ ${ }^{1}$ CSIRO Ecosystem Sciences, GPO Box 1700, Canberra, ACT 2601, Australia; \\ ${ }^{2}$ Department of Environment and Agriculture, Curtin University, GPO Box U1987, Perth WA 6845, Australia \\ Email: steve.shattuck@csiro.au,n.gunawardene@curtin.edu.au,b.heterick@curtin.edu.au
}

\begin{abstract}
Five species of the rarely encountered ant genus Probolomyrmex are known from Australia and Papua New Guinea, four of which are described here for the first time. Two species belong to the greavesi species-group (P. greavesi, $P$. latalongus $\mathbf{s p .} \mathbf{n}$.) while three belong to the longinodus species-group ( $P$. aliundus $\mathbf{s p .}$ n., $P$. newguinensis $\mathbf{s p .}$. n., $P$. simplex $\mathbf{s p}$. n.). The genus is now known to occur broadly across northern Australia and $P$. newguinensis and $P$. simplex are the first species of the genus described from Papua New Guinea. A key to Australian and Melanesian species is provided.
\end{abstract}

Key words: Formicidae, Probolomyrmex, Australian Region, new species, key

\section{Introduction}

Species of the enigmatic genus Probolomyrmex have been collected throughout the World's tropics and subtropics, with one species known from temperate south-eastern Australia and others from temperate China, Japan and South America. Since the time of Taylor's (1965) revision, the number of species has risen from nine to 20 (Agosti, 1994; Brown, 1975; Eguchi et al., 2006; Fisher, 2007; O'Keefe \& Agosti, 1997; Tanaka, 1974; Terayama \& Ogata, 1988; $\mathrm{Xu} \&$ Zeng, 2000). As cryptic ants with hypogean habits and on average about 20 workers per colony, it is not surprising that they are infrequently encountered. However, despite their diminutive size, it appears they have an ability to disperse widely. Probolomyrmex tani has been found throughout the island of Madagascar from habitats as diverse as montane forest to spiny bush (Fisher, 2007) and P. bidens was collected from an altitude of $2150 \mathrm{~m}$ in montane grassland in southern India (Brown, 1978).

Within the Indo-Pacific region Probolomyrmex species were divided into two species-groups by Eguchi et al. (2006), the P. greavesi group (with 7 species) and the P. longinodus group ( 9 species). Both species-groups occur from India east to Australia with the greavesi group extending on to the Solomon Islands (represented by $P$. salomonis), although only the longinodus group is known from Papua New Guinea. Most species have been collected a limited number of times and their true distributions are difficult or impossible to assess. Only two species are known from more than one country, with $P$. longinodus ranging from Japan to northern Thailand and $P$. vieti occurring from Thailand and Vietnam south to Java (Eguchi et al. 2006). Additionally, P. latalongus occurs across northern Australia from Cape York Peninsula to northern Western Australia (this study). Based on the distribution of $P$. tani in Madagascar, it seems likely that species of Probolomyrmex will show broader distribution ranges than current material indicates.

Within Australia specimens of Probolomyrmex have been collected from a variety of localities and habitats. For example, the type specimens for $P$. greavesi were collected from under a stone in an exotic pine plantation in the south-eastern corner of the continent. Probolomyrmex aliundus has been collected from rainforest litter in far northern Queensland while the final species, P. latalongus, has been found in habitats ranging from rainforest through Eucalyptus woodland to spinifex grasslands and occurs across the top of Australia from Queensland to Western Australia. This last species was recently collected on Barrow Island, Western Australia $\left(20^{\circ} 52.012^{\prime} \mathrm{S} 115^{\circ}\right.$ 24.349'E). This winged queen was collected in an intercept trap placed at ground level in a spinifex (Triodia) 
grassland $300 \mathrm{~m}$ from the beach. No workers were collected and it is possible that the specimen was blown in from the mainland, roughly $60 \mathrm{~km}$ away. However, the wings of this ant suggest that it is a weak flier and it has a strongly sclerotized body which is heavy in relation to the wing size. The potential for it to have been locally dispersed seems much more likely. Three male specimens of $P$. latalongus have been collected from northern Western Australia (near Derby) approximately $1000 \mathrm{~km}$ away while numerous workers (the type series for this species) were found in a Eucalyptus woodland near Darwin.

\section{Methods and abbreviations}

Size and shape characters were quantified and are reported as lengths or indices. Measurements were made with a stereo microscope using a dual-axis stage micrometer wired to digital readouts. The following measurements and indices are reported.

CI (cephalic index): HW/HL x 100.

HL: head length in full face view, measured from a line drawn across the anterior-most points of the clypeal fork teeth to the midpoint of a line drawn across the posterior margin of the head.

HTL: maximum length of hind tibia, excluding the proximal part of the articulation which is received into the distal end of the femur.

HW: maximum head width in full face view.

LPetI (lateral petiolar index): PtNL/PtH x 100.

ML: mesosomal (Weber's) length measured from the point at which the pronotum meets the cervical shield to the posterior base of the propodeal process, viewed laterally.

PetH: height of petiole in lateral view, measured vertically from the ventral margin of the posteroventral convexity/angle/projection of subpetiolar process to the level of the highest point of petiolar node.

PetNL: maximum length of petiolar node, measured longitudinally from the level of the anterolateral angle/ corner to that of the posteriormost extension of the petiolar tergum, where it surrounds the gastric articulation.

DPetW: maximum width of petiole viewed directly from above.

PronW: maximum width of the pronotum in dorsal view.

SI (scape index): SL/HW x 100.

SL: length of the scape (first antennal segment) excluding the basal constriction and condylar bulb.

Collections: ANIC, Australian National Insect Collection, Canberra, A.C.T.; CAS, California Academy of Sciences, San Francisco, California; CUAC, Curtin University Ant Collection, Perth, Western Australia; TERC, Tropical Ecosystems Research Centre, CSIRO, Darwin, Northern Territory.

\section{Key to Australian and Melanesian Probolomyrmex species based on workers}

1. Petiolar node relatively long and narrow (best viewed dorsally) (Fig. 1C), the dorsal face (in side view) uniformly convex and without a separation of the anterior and dorsal faces (Fig. 1B); scape relatively long, greater than half length of head (SI > 95,

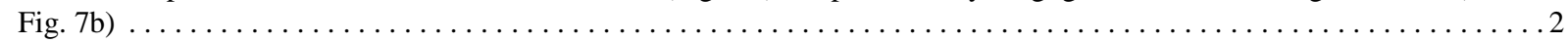
Petiolar node relatively short and broad (Fig. 2C) and with the anterior and dorsal faces separated by a convexity (Fig. 2B);

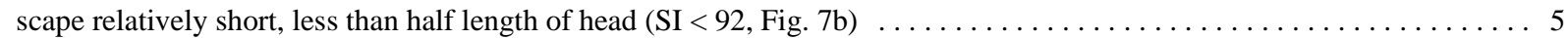

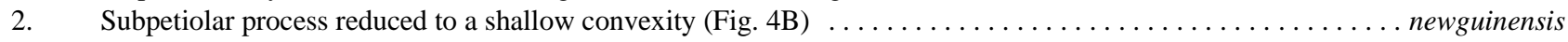

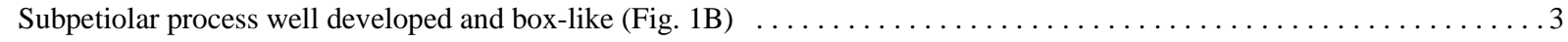

3. Posteroventral tooth of the subpetiolar process forming a $90^{\circ}$ angle (Fig. 1B); body larger (HL $>0.59 \mathrm{~mm}, \mathrm{HW}>0.38 \mathrm{~mm}$ )

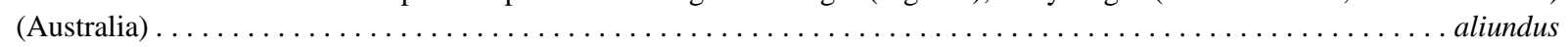
Posteroventral tooth of the subpetiolar process tooth-like (Fig. 5B); body smaller (HL $<0.59 \mathrm{~mm}, \mathrm{HW}<0.38 \mathrm{~mm})$ (Papua New

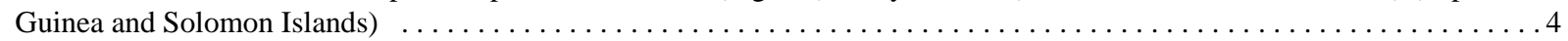

4. Anteroventral tooth of the subpetiolar process broadly rounded (Fig. 5B); posterior face of propodeum with lateral flanges weakly developed (Fig. 5B); foveae on mesosoma and gaster more strongly developed (Fig. 5B, C) (Solomon Islands) ......

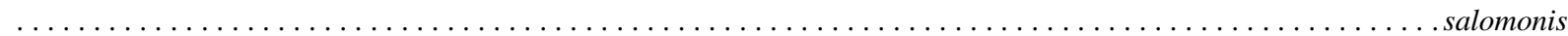
Anteroventral tooth of the subpetiolar process narrow and tooth-like (Fig. 6B); posterior face of propodeum with lateral flanges well developed (Fig. 6B); foveae on mesosoma and gaster weakly developed (Fig. 6B, C) (Papua New Guinea) .....

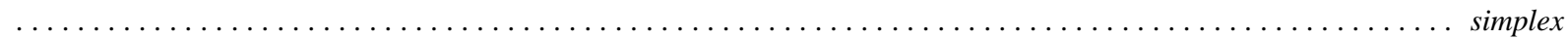

5. Body smaller (HW $<0.33 \mathrm{~mm}$ (Fig. 7a), $\mathrm{ML}<0.65 \mathrm{~mm})$, head narrower $(\mathrm{CI}<66$, Fig. 7a) (northern Australia) ... latalongus Body larger (HW >0.35mm (Fig. 7a), ML >0.65mm), head broader (CI > 66, Fig. 7a) (south-eastern Australia) ... greavesi 


\section{Probolomyrmex aliundus sp. $\mathbf{n}$.}

(Figs 1,7)

Types. Holotype worker from West Claudie River, Iron Range, Queensland, $12^{\circ} 45^{\prime} \mathrm{S}, 143^{\circ} 14^{\prime} \mathrm{E}, 5$ Dec. 1985 , G. Monteith (ANIC, ANIC32-030952). Paratypes: 4 workers and 3 dealate queens, same data as holotype (ANIC, ANIC32-011639, ANIC32-030950, ANIC32-030951).

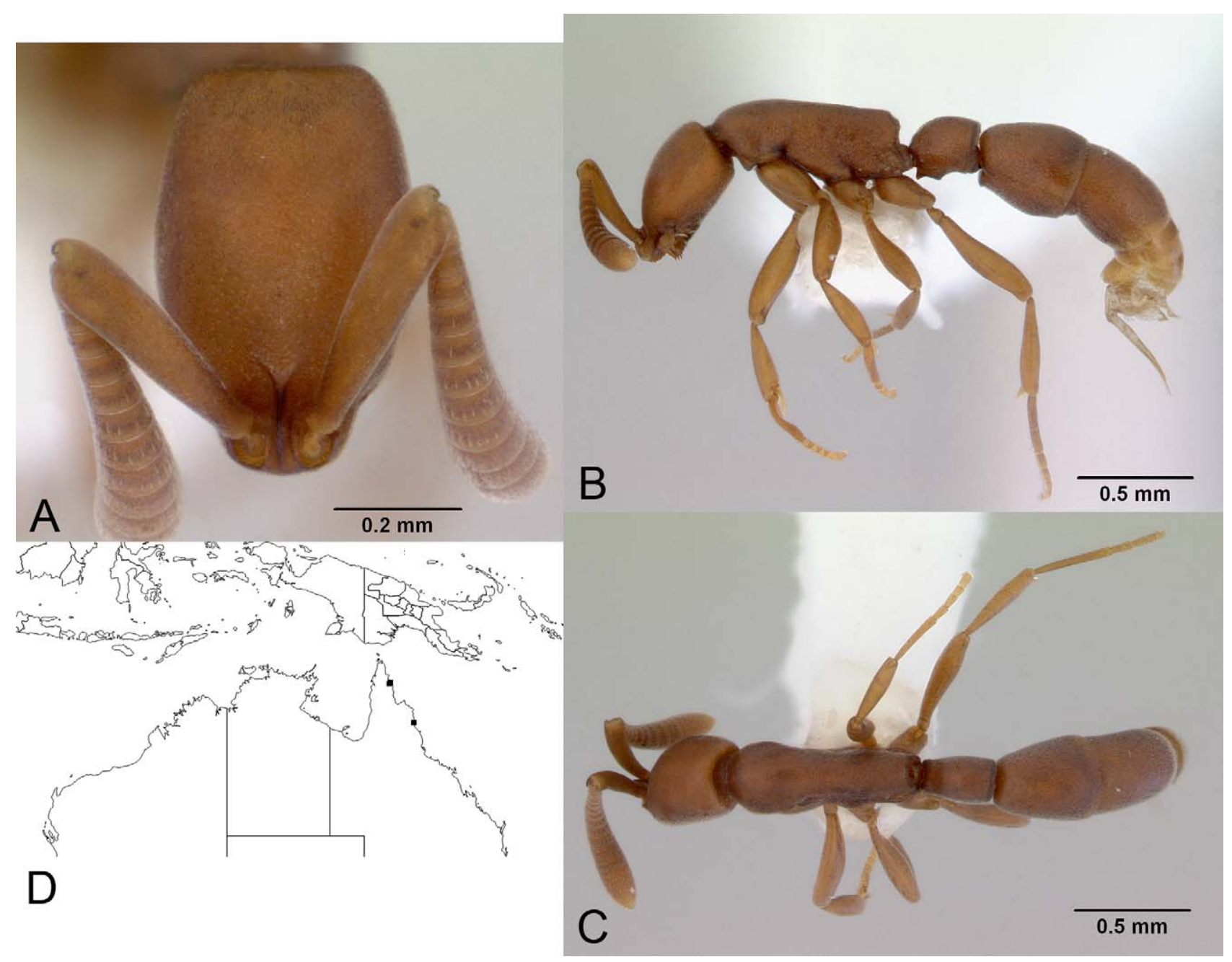

FIGURE 1. Probolomyrmex aliundus (holotype, West Claudie River, Queensland, ANIC32-030952): A. Front of head; B. Side of body; C. Top of body; D. Distribution of material examined.

Diagnosis. Petiolar node relatively long and narrow (best viewed dorsally), the dorsal face (in side view) uniformly convex and without a separation of the anterior and dorsal faces; posterior projection of the subpetiolar process forming a $90^{\circ}$ angle.

Probolomyrmex aliundus is similar to P. maryatiae (from Sabah, Malaysia) and will key to that species in Eguchi et al. (2006), and to P. simplex (from Papua New Guinea). The first two species differ in that the posterodorsal margin of the petiole in dorsal view is straight to weakly convex in $P$. aliundus (it is concave in $P$. maryatiae) and the posterior face of the node in lateral view is much less convex when compared to $P$. maryatiae (and more so than in P. vieti, another similar species from Indonesia and Thailand). Probolomyrmex aliundus differs from $P$. simplex in having less well developed and prominent foveae and in having the posteroventral tooth of the subpetiolar process angular rather than tooth-like. Probolomyrmex aliundus also averages larger than both $P$. maryatiae and P. simplex (HL $>0.59 \mathrm{~mm}$ vs. $<0.59 \mathrm{~mm}$, HW $>0.38 \mathrm{~mm}$ vs. $<0.38 \mathrm{~mm}$ ).

Worker description. Body ferruginous brown. Head in full-face view with weakly convex sides and weakly concave posterior margin. Eyes absent. Antennae relatively long. Dorsal outline of mesosoma essentially straight, the pronotum curving downwards slightly; posterior margin of propodeal dorsum in dorsal view straight; posterior 
face of propodeum margined laterally with a well-developed, thin, translucent lamella. Petiole including subpetiolar process longer than high, its dorsal surface in profile forming a relatively gentle and uniform curve; subpetiolar process with conspicuous anteroventral and posteroventral projections; the anteroventral projection forming a blunt tooth, the posteroventral projection forming a $90^{\circ}$ angle. Abdominal segment III (gastral segment I) in profile narrowed anteriorly, broadest near its posterior margin.

Measurements. Worker ( $\mathrm{n}=9$ ) - CI 60-64; DPetW 0.18-0.20; HL 0.59-0.65; HTL 0.30-0.47; HW 0.38-0.40; LPetI 99-111; ML 0.77-0.88; PetH 0.27-0.29; PetNL 0.27-0.33; PronW 0.29-0.31; SI 96-112; SL 0.36-0.44

Additional material examined (ANIC). Australia: Queensland: $1.5 \mathrm{~km}$ EbyN Mt. Sorrow (Calder, A. \& Weir, T.); $11 \mathrm{~km}$ ENE Mt. Tozer (Weir, T.A.); Cape Tribulation (Monteith, G. ); West Claudie River, Iron Range (Taylor, R.W. \& Lawrence, J.F.).

Comments. This rarely encountered species is known from a limited number of collections made in rainforest on Cape York Peninsula, Queensland.

\section{Probolomyrmex greavesi Taylor}

Probolomyrmex greavesi Taylor, 1965: 358.

(Figs 2,7)

Types. Holotype worker from Mt. Stromlo, A.C.T., 11 Mar. 1933, T. Greaves (ANIC, ANIC32-011633). Paratypes: 2 workers, 2 queens and 1 male, same data as holotype (ANIC, 1 worker, 1 queen and 1 male ANIC32-030938, 1 worker ANIC32-030939, 1 queen ANIC32-030937); 3 workers, same data as holotype except 28 Jan. 1933 (ANIC, ANIC32-011634); 1 worker from Greenmount, Queensland, 4 Dec. 1949, T. Greaves (ANIC, ANIC32-011635).

Diagnosis. Petiolar node relatively short and broad and with the anterior and dorsal faces separated by a convexity; subpetiolar process forming a rounded $90^{\circ}$ angle anteriorly and with the ventral margin straight; body large (HW >0.35mm, ML > 0.65mm) and head broad (CI > 66).

Probolomyrmex greavesi is similar to P. latalongus (from Australia) and P. vieti (from Thailand, Vietnam and Indonesia). It differs from $P$. latalongus by its larger size (HW $>0.35 \mathrm{~mm}$ and $\mathrm{ML}>0.65 \mathrm{~mm}$ vs. $\mathrm{HW}<0.33 \mathrm{~mm}$ and $\mathrm{ML}<0.65 \mathrm{~mm}$ in P. latalongus) and broader head (CI $>66$ vs. CI $<66$ in P. latalongus), and from P. vieti by the anteriorly angular and ventrally straight subpetiolar process (the process having an anterior tooth and concave ventral surface in $P$. vieti).

Worker description. Body light ferruginous brown. Head in full-face view with weakly convex sides and very shallowly concave occipital border. Eye absent. Antenna relatively short. Dorsal outline of mesosoma straight; posterior margin of dorsum of propodeum in dorsal view moderately concave; posterior face of propodeum separated from sides by an angle, the lamella being absent. Petiole including subpetiolar process higher than long, in profile with relatively steep anterior face and convex posterior outline; posterodorsal margin of petiolar node in dorsal view very weakly concave; subpetiolar process developed; its anteroventral portion forming a rounded $90^{\circ}$ angle; posteroventral portion of subpetiolar process forming a blunt tooth; ventral surface straight. Abdominal segment III (gastral segment I) in profile relatively short, gently narrowed anteriad in the anterior $2 / 3$; abdominal sternum III weakly convex behind the midlength.

Measurements. Worker (n=5)—CI 67-69; DPetW 0.18-0.20; HL 0.52-0.58; HTL 0.32-0.37; HW 0.36-0.39; LPetI 80-88; ML 0.66-0.77; PetH 0.26-0.29; PetNL 0.22-0.25; PronW 0.26-0.28; SI 83-90; SL 0.31-0.35

Additional material examined (in ANIC except where noted). Australia: Australian Capital Territory: Mt. Ainslie, W Face (Brooks, C.G.). New South Wales: 23km NW Batemans Bay (Shattuck, S.O.).

Comments. This was the first species of Probolomyrmex described from Australia and before this study it was generally assumed to be the only species occurring there. However, it is now known that this species is restricted to south-eastern Australia while two separate species occur in northern Australia, P. aliundus on Cape York Peninsula and P. latalongus across much of northern Australia.

Probolomyrmex greavesi has been found in forested sites ranging from a non-native pine plantation through dry sclerophyll and into wet sclerophyll. It is known to nest in soil under rocks. It is one of the rarer Australian ants having been collected only a handful of times. 


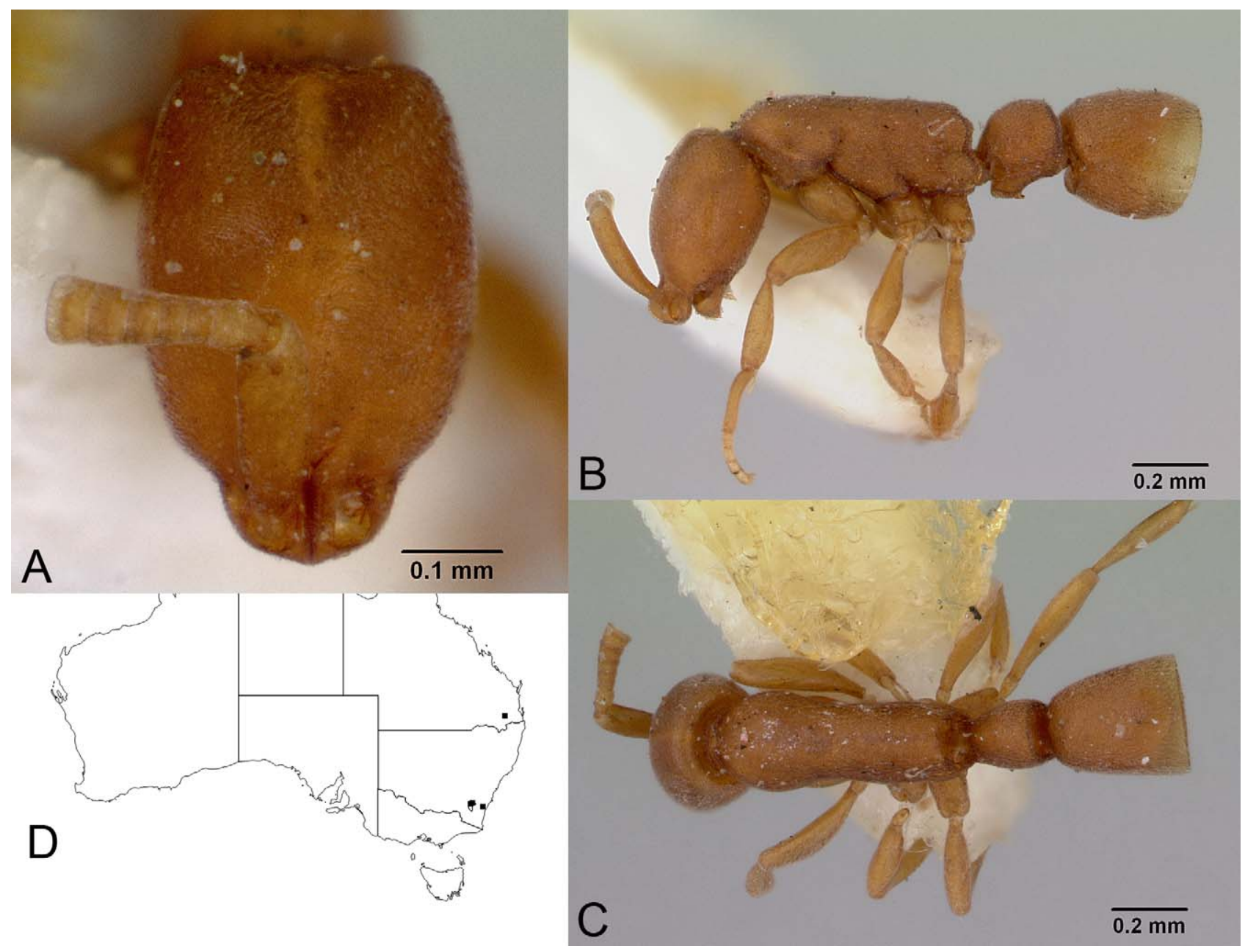

FIGURE 2. Probolomyrmex greavesi (holotype, Mt. Stromlo, A.C.T., ANIC32-011633): A. Front of head; B. Side of body; C. Top of body; D. Distribution of material examined.

\section{Probolomyrmex latalongus sp. $\mathbf{n}$.}

(Figs 3, 7)

Types. Holotype worker from Solar Village survey, Darwin, Northern Territory, Feb. 2002, A.N. Andersen, unburnt slope 1, litter sample (ANIC, ANIC32-066457). Paratypes: 16 workers, same data as holotype (5 in ANIC, ANIC32-011632; 11 in TERC).

Diagnosis. Petiolar node relatively short and broad and with the anterior and dorsal faces separated by a convexity; subpetiolar process forming a rounded $90^{\circ}$ angle anteriorly; body small (HW $<0.33 \mathrm{~mm}$, ML < $0.65 \mathrm{~mm})$ and head narrow $(\mathrm{CI}<66)$.

Probolomyrmex latalongus is similar to $P$. greavesi (from Australia) and P. vieti (from Thailand, Vietnam and Indonesia). It differs from both by its smaller size and from $P$. vieti by the anteriorly angular subpetiolar process (the process having an anterior tooth in $P$. vieti).

Worker description. Body ferruginous brown. Head in full-face view with weakly convex sides and very shallowly concave occipital border. Eye absent. Antenna relatively short. Dorsal outline of mesosoma straight; posterior margin of dorsum of propodeum in dorsal view weakly concave; posterior face of propodeum separated from sides by a sharp angle, the lamella being very weakly developed. Petiole including subpetiolar process slightly higher than long, in profile with relatively steep anterior face and straight posterior outline; posterodorsal margin of petiolar node in dorsal view very weakly concave; subpetiolar process developed; its anteroventral portion forming a rounded $90^{\circ}$ angle; posteroventral portion of subpetiolar process forming a blunt tooth; ventral surface straight to concave. Abdominal segment III (gastral segment I) in profile relatively short, gently narrowed anteriad in the anterior $2 / 3$; abdominal sternum III weakly and uniformly convex. 
Measurements. Worker (n=9)—CI 62-65; DPetW 0.13-0.16; HL 0.46-0.51; HTL 0.25-0.30; HW 0.29-0.32; LPetI 88-98; ML 0.54-0.65; PetH 0.20-0.24; PetNL 0.19-0.22; PronW 0.22-0.25; SI 79-91; SL 0.24-0.28

Additional material examined. (in ANIC except where noted). Australia: Queensland: $11 \mathrm{~km}$ ENE Mt. Tozer (Weir, T.A.); Cape Tribulation area (Calder, A. \& Weir, T.); Mossman Bluff Track, 5-10km W Mossman (Monteith, Thompson \& ANZSES); Mt. Webb Natl. Park (Calder, A. \& Feehan, J.). Western Australia: Barrow Island (Gunawardene, N. \& Taylor, C.) (CUAC); Langi Crossing (Ross, E.S. \& Cavagnaro, D.Q.) (CAS).

Comments. This is by far the most widely distributed species of Probolomyrmex in Australia. It ranges across northern Australia from Barrow Island in the west to Cape York Peninsula in the east. It also occurs in a wide range of habitats, from rainforests on Cape York Peninsula to Eucalyptus woodland in the Top End of the Northern Territory (Andersen et al., 2006) to grasslands on Barrow Island, Western Australia. Most encounters have been from leaf litter samples but one collection involved pitfall traps while another was a queen from a flight intercept trap.

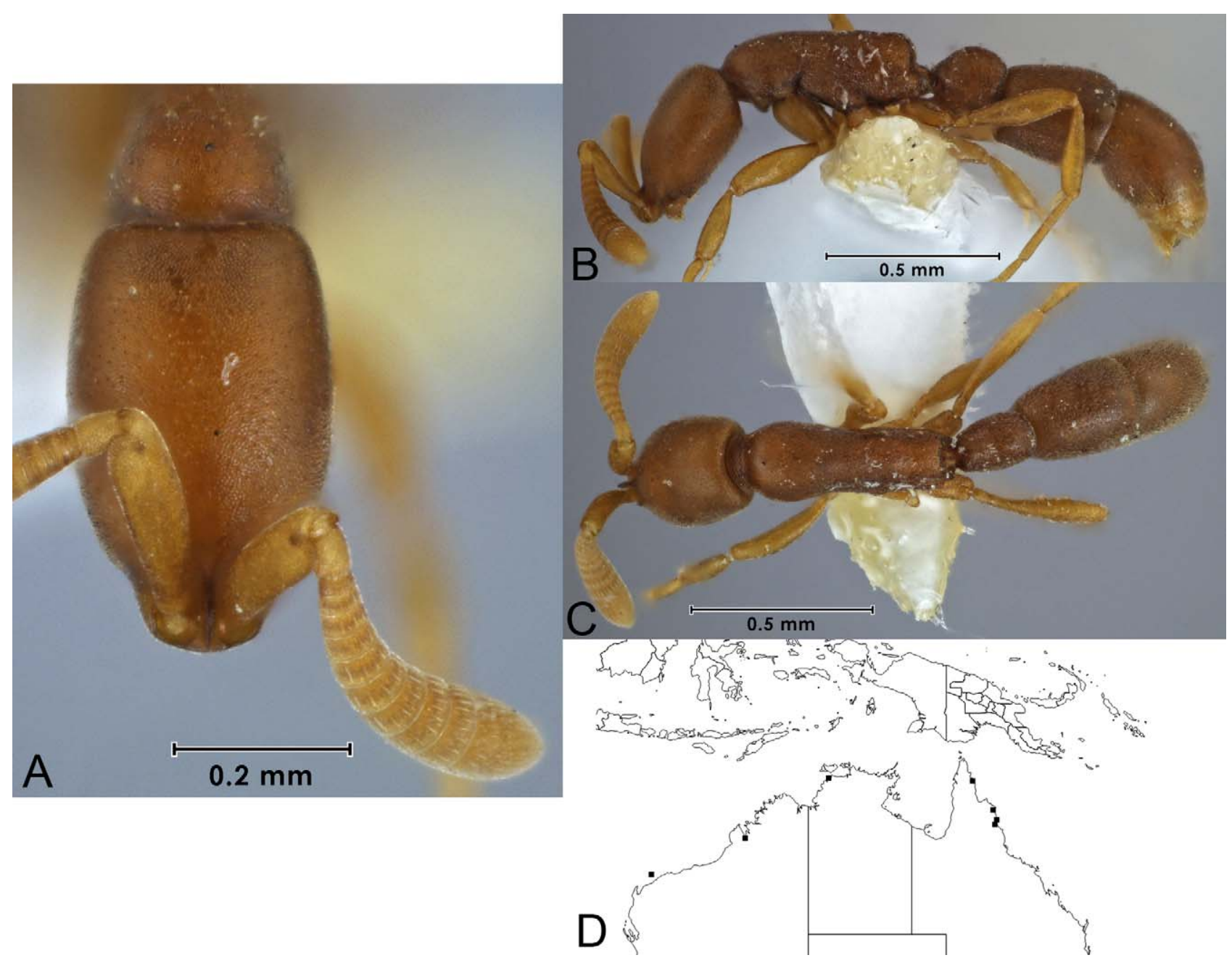

FIGURE 3. Probolomyrmex latalongus (paratype, Solar Village survey, Darwin, Northern Territory, ANIC32-011632): A. Front of head; B. Side of body; C. Top of body; D. Distribution of material examined.

\section{Probolomyrmex newguinensis sp. n.}

(Fig. 4)

Types. Holotype worker from Bulolo, Morobe District, Papua New Guinea, 31 Dec. 1970, B.B. Lowery, regenerated rainforest and bamboo, under small mossy rock in jet black soil (ANIC, ANIC32-066450). Paratypes: 8 workers and 1 male (missing head), same data as holotype (ANIC, ANIC32-066468).

Diagnosis. Petiolar node relatively long and narrow (best viewed dorsally), the dorsal face (in side view) moderately convex anteriorly and weakly convex posteriorly; posterodorsal margin of petiole in dorsal view produced medially into a rearward directed rounded projection; subpetiolar process reduced to a shallow convexity. 
Probolomyrmex newguinensis is morphologically similar to $P$. watanabei from Malaysia, particularly in the shape of the petiole. It differs from that species in having the petiole more barrel-shaped in dorsal view rather than trapezoidal, and in having the anterior face of the node (in side view) more strongly convex, giving the petiole a higher appearance. Additionally, the head is more elongate (CI <61 vs. $>62$ ) and the scape is shorter (SI < 114 vs. $>124$ ).

Worker description. Body dark ferruginous brown. Head in full-face view with weakly convex sides and weakly and broadly concave posterior margin. Eyes absent. Antennae moderately long. Dorsal outline of mesosoma very weakly convex with a slight concavity at the metanotal groove; posterior margin of propodeal dorsum in dorsal view drawn posteriorly into a broad, rounded projection; posterior face of propodeum angled laterally and lacking a well-developed lamella. Petiole including subpetiolar process longer than high, its dorsal surface in profile relatively strongly convex anteriorly and rounding into a weakly convex to nearly flat surface posteriorly; subpetiolar process reduced to a weak convexity. Abdominal segment III (gastral segment I) in profile narrowed anteriorly, the ventral surface concave anteriorly and convex posteriorly.

Measurements. Worker ( $\mathrm{n}=6$ ) - CI 59-61; DPetW 0.21-0.24; HL 0.71-0.75; HTL 0.50-0.55; HW 0.43-0.46; LPetI 118-123; ML 0.97-1.03; PetH 0.30-0.31; PetNL 0.35-0.37; PronW 0.36-0.37; SI 110-114; SL 0.48-0.51

Comments. Probolomyrmex newguinensis has been collected only once from a nest under a rock in a regenerated rainforest in Papua New Guinea.

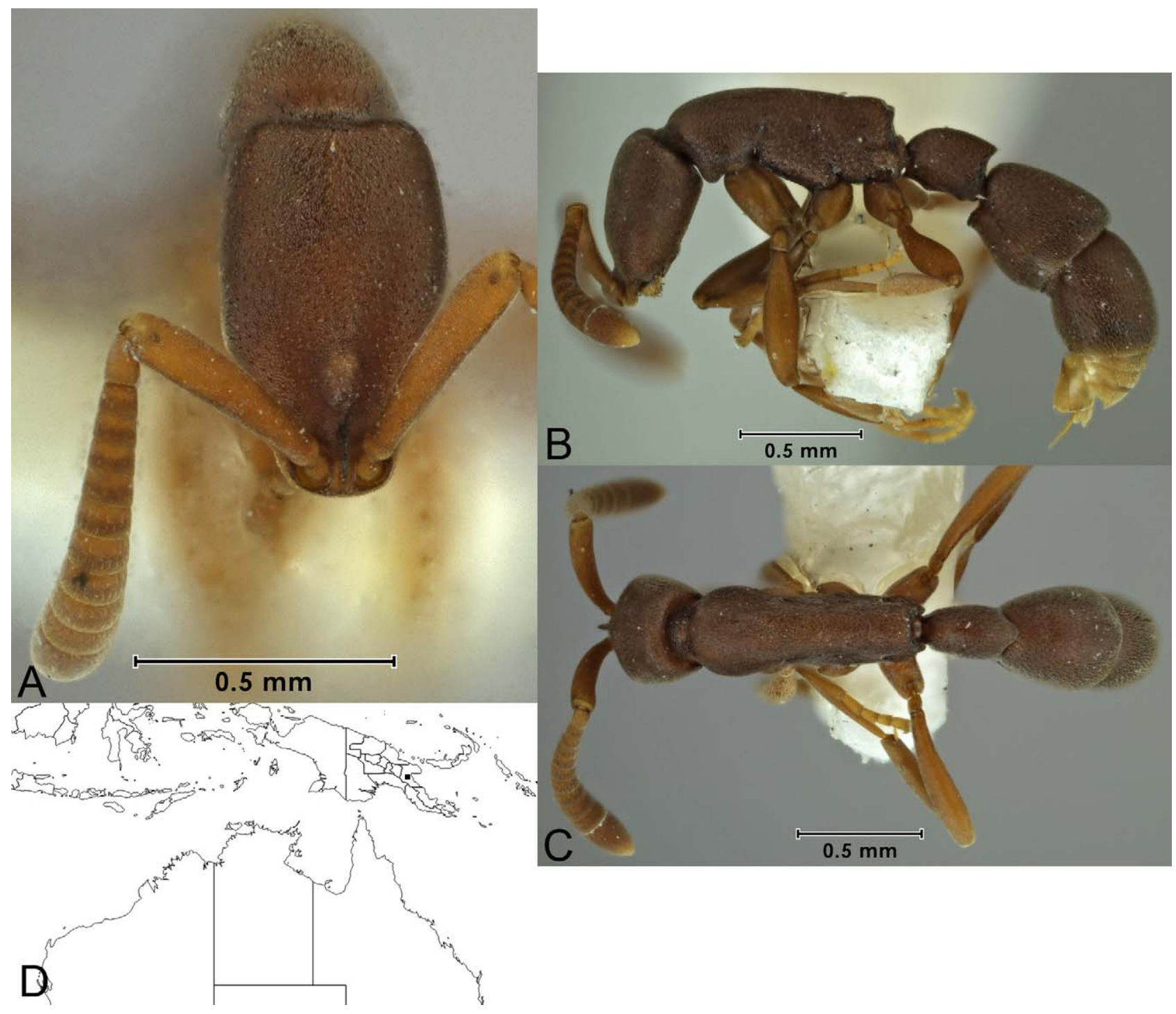

FIGURE 4. Probolomyrmex newguinensis (holotype, Bulolo, Morobe District, Papua New Guinea, ANIC32-066450): A. Front of head; B. Side of body; C. Top of body; D. Distribution of material examined. 


\section{Probolomyrmex salomonis Taylor}

Probolomyrmex salomonis Taylor, 1965: 358.

(Fig. 5)

Diagnosis. Petiolar node relatively long and narrow (best viewed dorsally), the dorsal face (in side view) uniformly convex and without a separation of the anterior and dorsal faces; anterior projection of the subpetiolar process broadly rounded, the posterior projection in the form of a blunt tooth.

Probolomyrmex salomonis is most similar to P. simplex from Papua New Guinea. It differs in having the anteroventral tooth of the subpetiolar process broadly rounded rather than narrow and tooth-like, the lateral flanges on the posterior face of the propodeum more weakly developed and in having the foveae on the mesosoma and gaster more strongly developed.

Comments. This species is restricted to the Solomon Islands where it is known from a handful of collections made in forested situations. For a morphological description and further details see Taylor (1965).

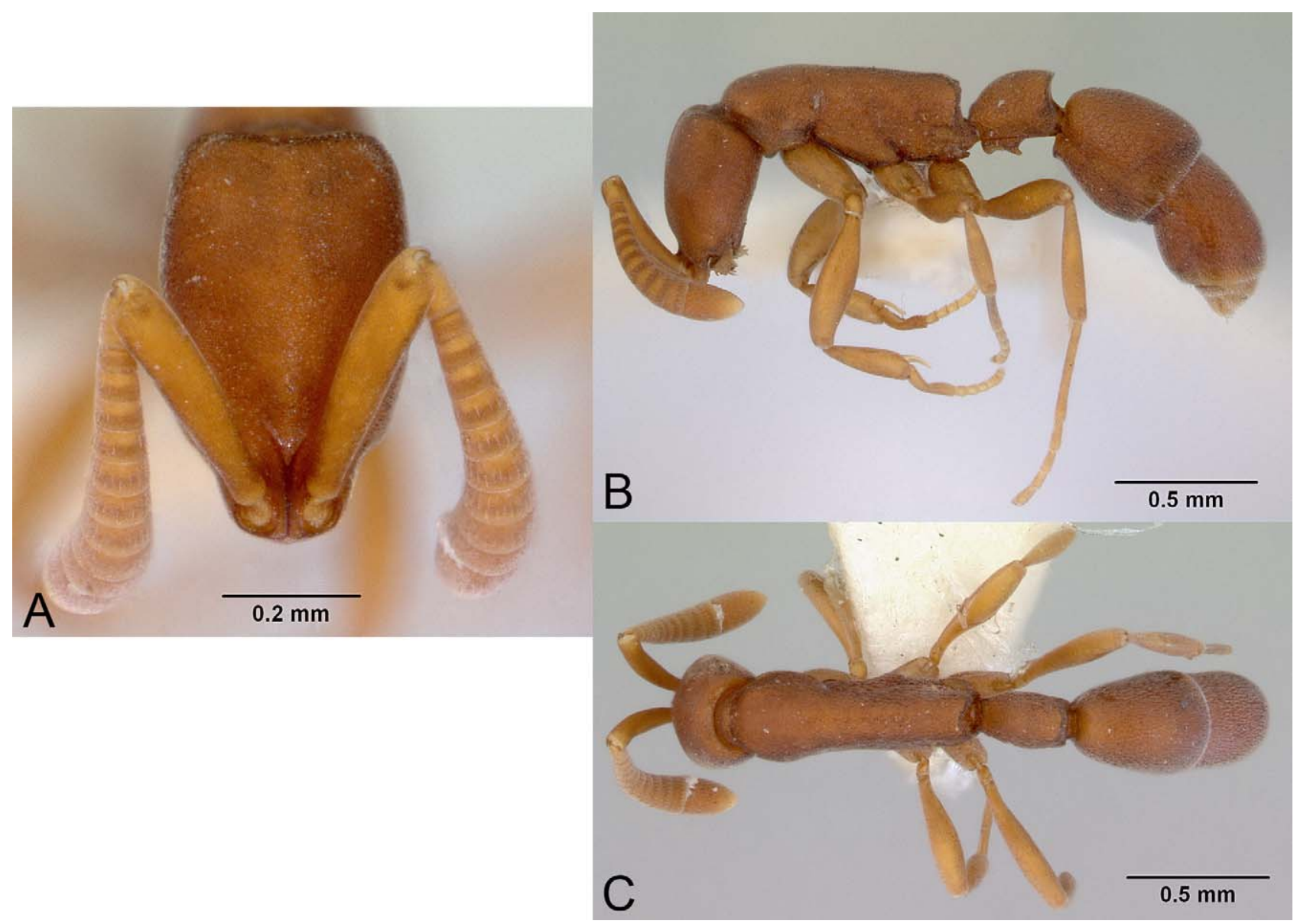

FIGURE 5. Probolomyrmex salomonis (Huni River, San Cristoval, Solomon Islands, CASENT0172413): A. Front of head; B. Side of body; C. Top of body.

\section{Probolomyrmex simplex sp. $\mathbf{n}$.}

(Fig. 6)

Types. Holotype worker from Popondetta, Northern District, Papua New Guinea, 15 Feb. 1972, P.M. Room (ANIC, ANIC32-028437). Paratypes: 4 workers, same data as holotype (ANIC, ANIC32-028436, ANIC32028438, ANIC32-028439, ANIC32-028440).

Diagnosis. Petiolar node relatively long and narrow (best viewed dorsally), the dorsal face (in side view) uniformly convex and without a separation of the anterior and dorsal faces; posterior projection of the subpetiolar process in the form of a blunt tooth. 
Probolomyrmex simplex is similar to the Australian species P. aliundus, P. salomonis from the Solomon Islands and the Malaysian P. maryatiae. It differs from P. aliundus in being smaller (HL $<0.59 \mathrm{~mm}$ vs. $>0.59 \mathrm{~mm}$, HW < $0.38 \mathrm{~mm}$ vs. $>0.38 \mathrm{~mm}$ ), having more strongly developed foveae and in having the posteroventral tooth of the subpetiolar process tooth-like rather than angular. It can be separated from $P$. salomonis in having the anteroventral tooth of the subpetiolar process narrow and tooth-like rather than broadly rounded, having relatively well developed lateral flanges on the posterior face of propodeum and in having the foveae on the mesosoma and gaster weakly rather than strongly developed. It differs from P. maryatiae in that the posterodorsal margin of the petiole in dorsal view is straight to weakly convex rather than concave as in $P$. maryatiae and in having the posterior face of the petiolar node in lateral view is much less convex.

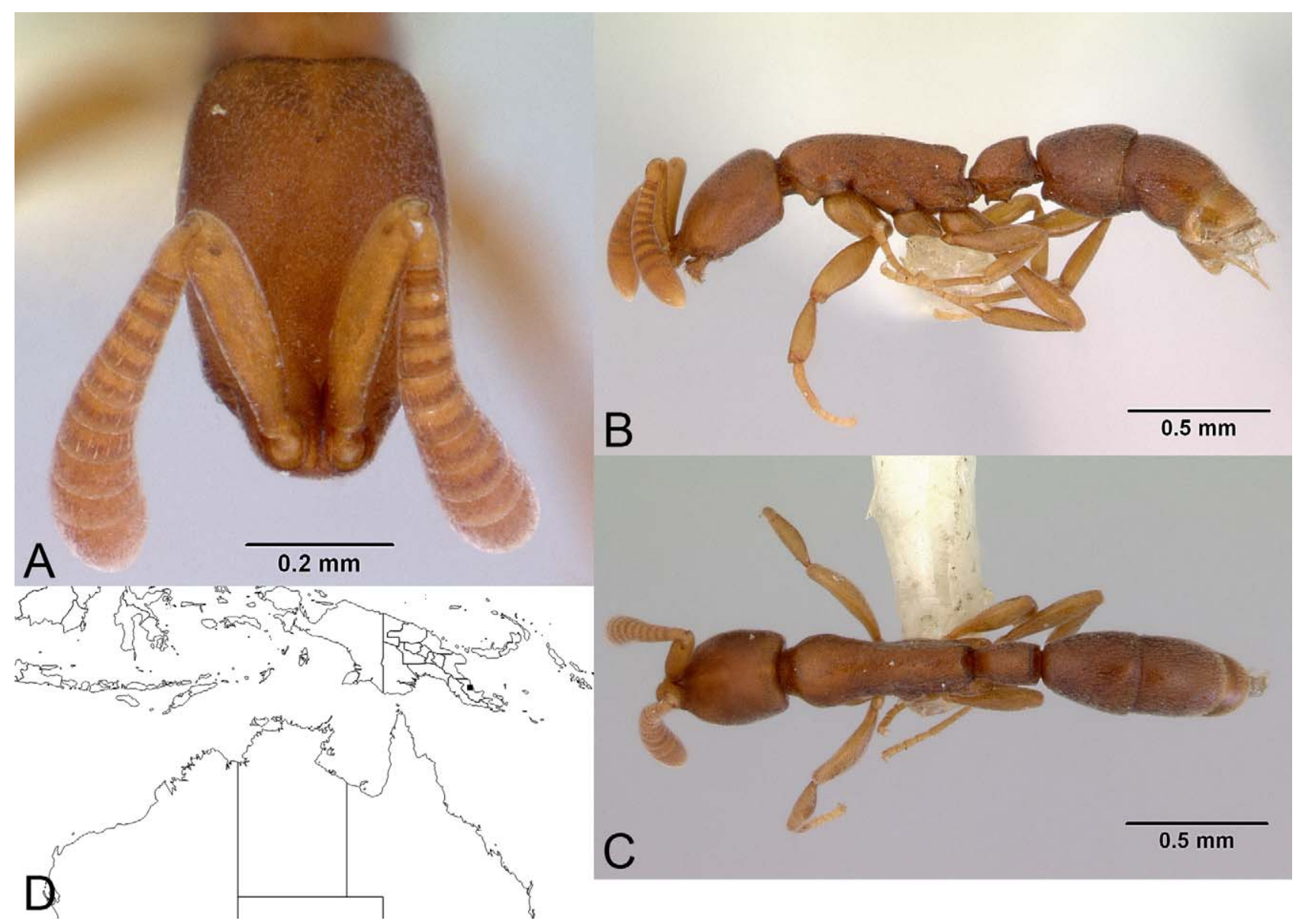

FIGURE 6. Probolomyrmex simplex (holotype, Popondetta, Northern District, Papua New Guinea, ANIC32-028437): A. Front of head; B. Side of body; C. Top of body; D. Distribution of material examined.

Worker description. Body ferruginous brown. Head in full-face view with weakly convex sides and weakly concave posterior margin. Eyes absent. Antennae relatively long. Dorsal outline of mesosoma essentially straight, the pronotum curving downwards slightly and the propodeal dorsum raised slightly; posterior margin of propodeal dorsum in dorsal view straight; posterior face of propodeum margined laterally with a well-developed, thin, translucent lamella. Petiole including subpetiolar process approximately as long as high, its dorsal surface in profile forming a relatively gentle and uniform curve with only a slightly stronger curve near the border of the anterior and posterior faces; subpetiolar process with conspicuous anteroventral and posteroventral projections, both in the form of a blunt tooth. Abdominal segment III (gastral segment I) in profile narrowed anteriorly, broadest near its posterior margin, the ventral surface uniformly convex.

Measurements. Worker ( $\mathrm{n}=4$ ) - CI 62-64; DPetW 0.16-0.17; HL 0.57-0.59; HTL 0.35-0.38; HW 0.35-0.38; LPetI 104-108; ML 0.73-0.79; PetH 0.24-0.26; PetNL 0.26-0.27; PronW 0.28-0.29; SI 96-102; SL 0.35-0.37

Comments. This species is presently known from a single small collection made many years ago in Northern Province, Papua New Guinea. 


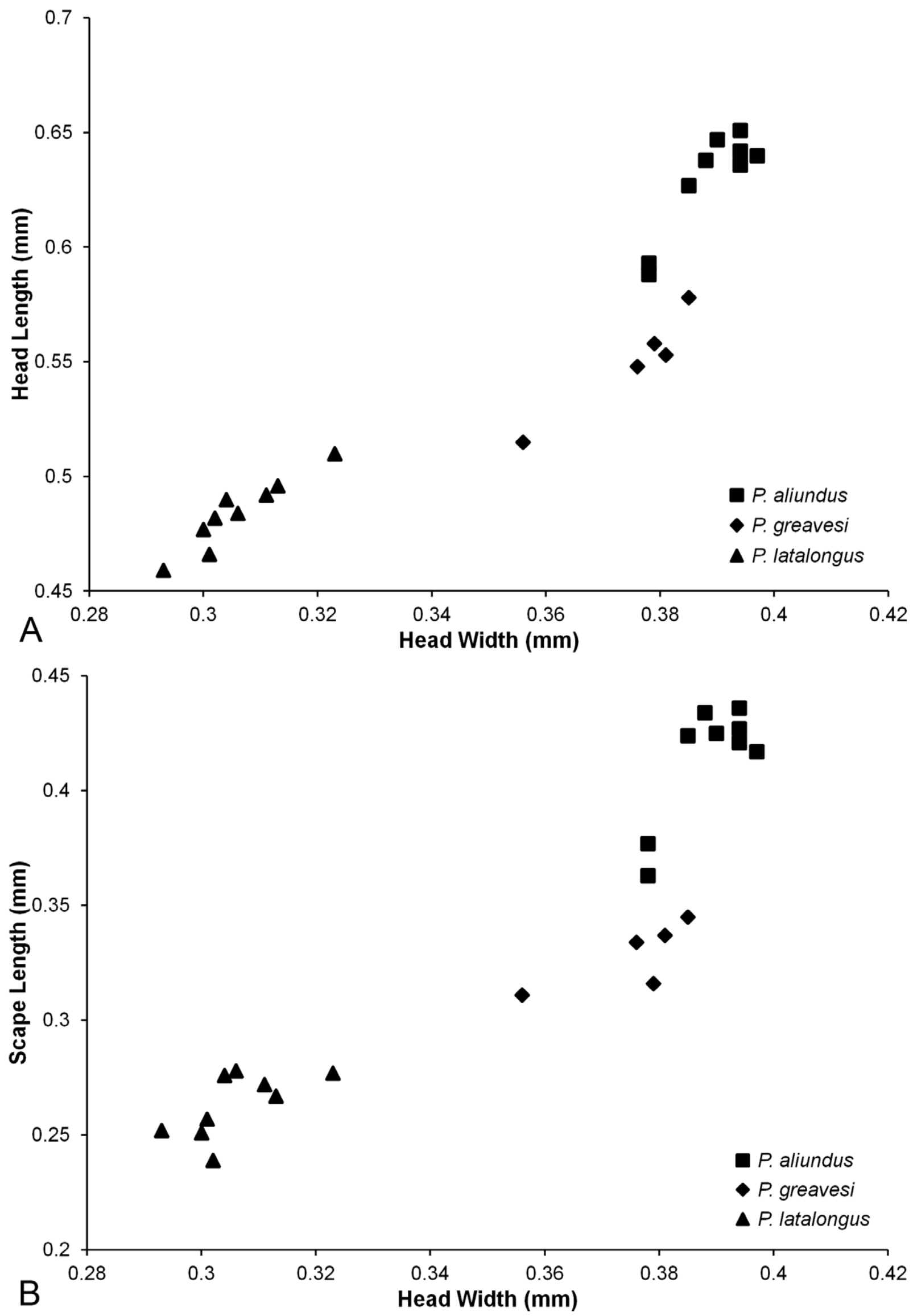

FIGURE 7 . A. Head length versus head width for P. aliundus, P. greavesi and P. latalongus; B. Scape length versus head width for $P$. aliundus, $P$. greavesi and $P$. latalongus. 


\section{Acknowledgements}

Special thanks to Bob Taylor (Canberra, ACT) for recognising the Papua New Guinea species as being undescribed. Selected images were prepared by April Nobile, California Academy of Sciences. Valuable comments on this manuscript were provided by Francisco Hita Garcia, Bob Taylor and Jack Longino.

\section{References}

Agosti, D. (1994) A revision of the South American species of the ant genus Probolomyrmex (Hymenoptera: Formicidae). Journal of the New York Entomological Society, 102, 429-434.

Andersen, A.N., Hertog, T. \& Woinarski, J.C.Z. (2006) Long-term fire exclusion and ant community structure in an Australian tropical savanna: congruence with vegetation succession. Journal of Biogeography, 33, 823-832.

Brown, W.L., Jr. (1975) Contributions toward a reclassification of the Formicidae. 5. Ponerinae, tribes Platythyreini, Cerapachyini, Cylindromyrmecini, Acanthostichini, and Aenictogitini. Search Agriculture 5. Entomology (Ithaca), 15, $1-115$.

Brown, W.L., Jr. (1978) Contributions toward a reclassification of the Formicidae. Part VI. Ponerinae, tribe Ponerini, subtribe Odontomachiti. Section B. Genus Anochetus and bibliography. Studia Entomologica, 20, 549-638.

Eguchi, K., Yoshimura, M. \& Yamane, S. (2006) The Oriental species of the ant genus Probolomyrmex (Insecta: Hymenoptera: Formicidae: Proceratiinae). Zootaxa, 1376, 1-35.

Fisher, B.L. (2007) A new species of Probolomyrmex (Hymenoptera: Formicidae) from Madagascar. Pp. 146-152 in Snelling, R. R., Fisher, B. L. \& Ward, P. S. (eds.). Advances in ant systematics (Hymenoptera: Formicidae): homage to E. O. Wilson - 50 Years of contributions. Memoirs of the American Entomological Institute, 80.

O'Keefe, S.T. \& Agosti, D. (1997) A new species of Probolomyrmex (Hymenoptera: Formicidae) from Guanacaste, Costa Rica. Journal of the New York Entomological Society, 105, 190-192.

Tanaka, M. (1974) Description of a new species of ant of the genus Probolomyrmex from Malaysia. Entomological Review of Japan, 26, 35-37.

Taylor, R.W. (1965) A monographic revision of the rare tropicopolitan ant genus Probolomyrmex Mayr (Hymenoptera: Formicidae). Transactions of the Royal Entomological Society of London, 117, 345-365.

Terayama, M. \& Ogata, K. (1988) Two new species of the ant genus Probolomyrmex (Hymenoptera, Formicidae) from Japan. Kontyu, 56, 590-594.

Xu, Z. \& Zeng, G. (2000) Discovery of the worker caste of Platythyrea clypeata Forel and a new species of Probolomyrmex Mayr in Yunnan, China. Entomologia Sinica, 7, 213-217. 